\title{
Adenosarcoma of the corpus uteri
}

INSERM

\section{Source}

INSERM. (1999). Orphanet: an online rare disease and orphan drug data base.

Adenosarcoma of the corpus uteri. ORPHA:213600

Adenosarcoma of the corpus uteri is a rare subtype of mixed epithelial-mesenchymal tumor, often presenting as a large, exophytic polypoid lesion, which may extend through the cervix, composed of benign or atypical epithelium and low-grade malignant stroma. It usually presents with dysfunctional bleeding or vaginal discharge and less often abdominal pain. Association with long-term unopposed estrogen therapy, tamoxifen therapy and a history of pelvic radiation has been reported. 